\title{
Estimation of the on-farm-costs of soil erosion in Sleman, Indonesia
}

\author{
A. Möller \& U. Ranke \\ Federal Institute for Geosciences and Natural Resources (BGR), \\ Hannover, Germany
}

\begin{abstract}
Soils are non-renewable resources. World-wide in many regions a sustainable use of soils is endangered through anthropogenic accelerated soil erosion. From the economic point of view erosion protection is the transfer soil use potential into the future. However, in developing countries such as Indonesia usually only short term profit counts and consequently soil resources suffer from accelerated exploitation. Advising farmers that soil erosion protection measures not only ensure a prolonged agricultural potential for the future, but can also include economic benefits is a promising attempt to promote the use of soil erosion protection measures. The prerequisite for the decision process on a farm level is the possibility to estimate the costs of soil erosion. In Indonesia mostly reliable data are missing, and also no expensive surveys can be accomplished. Therefore, less data intensive methods such as the "replacement cost" or the "productivity change" method were used to estimate the "on-farm-costs" of soil erosion in Sleman on Java. The "replacement cost" method resulted in clearly higher costs compared to the "productivity change" method. This is due to an over-estimation of the costs by the "replacement cost" method. The use of both methods comparing costs and benefits of soil protection measures indicate similar decision guidelines. However, more information is necessary on the additional effects of soil conservation and political constraints to be a base for sound decision-making on a farm level, but making information available on the benefits of conservation measures helps farmers in their decision process to invest in soil conservation. Beyond this, soil erosion is also a societal problem, including external costs making up a large portion of the economic effects of soil erosion.
\end{abstract}

Keywords: soil erosion, on-farm costs, replacement cost method, productivity change. 


\section{Introduction}

Land conversion within the developing world is occurring at an unprecedented rate. Expansion of subsistence farming practices in the form of field crop agriculture and pasture within rural areas is contributing significantly to ecological alteration in many tropical countries (Uhl et al. [1]; Landa et al. [2]; Lubchenco [3]).

Soil erosion is thereby a major environment threat for the sustainability and productive capacity of agriculture. During the last 40 years, nearly one third of the world's arable land has been lost by erosion and continues to be lost at a rate of more than 10000 million hectares per year (Pimentel et al. [4]).

In Indonesia more than $50 \%$ is mountainous and consequently highly vulnerable towards soil erosion. On Java about 23.7 million hectares are stated to be "critical" land concerning soil erosion.

Erosion adversely affects soil quality and productivity by reducing nutrients, infiltration rates, water-holding capacity, organic matter, soil biota, and soil depth. Several studies have shown a reduction of soil productivity in the long term between 2 and 70\% for many soils (Wolman [5]). The main reduction of soil productivity in the short term is thereby due to the loss of soil nutrients and water availability. In the long term the loss of soil depth, water holding capacity and organic matter can contribute largely to the loss of soil productivity.

While it is widely accepted that erosion lowers agricultural productivity, there is little agreement on exactly how productivity is related to erosion or on the quantitative impact of erosion on yields (Magrath and Arens [6]). Erosion involves changes in the availability and relative concentration of nutrients for plant growth and changes in the soil structure which influences root growth and affects the availability of water.

On the other hand, soils get differently affected by erosion based on their individual fertility. They range form soils whose natural fertility is accumulated, along with the soil organic matter, in the top few centimetres only, to soils being fertile throughout the whole profile. Furthermore, different crops get differently affected by a potential loss of soil productivity. Demanding crops may react with high yield reductions, while non-demanding crops like Alfalfa may only be little affected.

In measuring the on-site costs of soil erosion the main objective is usually to estimate the present value of net income lost through excessive (i.e. sub-optimal) soil erosion. According to Barbier [7], to be an economic cost, the onsite costs of soil erosion must be an opportunity cost, which is defined as the value of a forgone alternative like the investment in soil conservation. Because soil conservation is not costless, the on site cost of soil erosion must be the loss in the long-run net profitability of the farming system not investing in soil conservation, providing of course that such an investment is an economically worthwhile alternative. The on-site costs of soil erosion are than the difference between the net returns of the farming system with soil conservation and the net returns with erosion (Barbier [7]). 
Although the methodology seems to be the best choice to estimate the onsite costs of soil erosion, it has often proven to be very difficult to implement empirically. It is not easy to determine an economically viable alternative conservation investment to current erosive practices. Particularly, in developing regions such as Southeast Asia, with diverse and heterogeneous small-scale farming systems, the data constraints are often enormous, whereas simplifying assumptions and generalizations may be misleading.

Therefore, the On-site costs of soil erosion were estimated in this study based on alternative empirical models determining changes in soil productivity, or the costs to replace the lost nutrients, water, eroded topsoil or organic matter (Kim and Dixon [8]; Magrath and Arens [6]; Dixon et al. [9]; Gunatilake and Vieth [10]; Krausse et al. [11]).

These approaches may by less reliable or even second-best from an economic perspective, but they were the only implementable choices based on the data available. Especially the data required for the replacement cost approach are easier to generate in developing countries.

\section{Site description}

The Kabupaten Sleman is situated in the northern part of the province of Yogyakarta (Figure 1). It is located at the southern flank of the Merapi volcano starting almost from see level in the south to the top of the volcano at an altitude of $2986 \mathrm{~m}$.

The Climate in Sleman is humid tropical with a distinct dry season from Mai until October. The average annual rainfall rages between less than $1500 \mathrm{~mm}$ and $3300 \mathrm{~mm}$. Heavy rainfalls with more than $100 \mathrm{~mm}$ per day or within a period of three days are common. These storms are a major driving force of heavy soil erosion and can trigger Lahars (mud flows) at the upper slopes of Mt. Merapi.

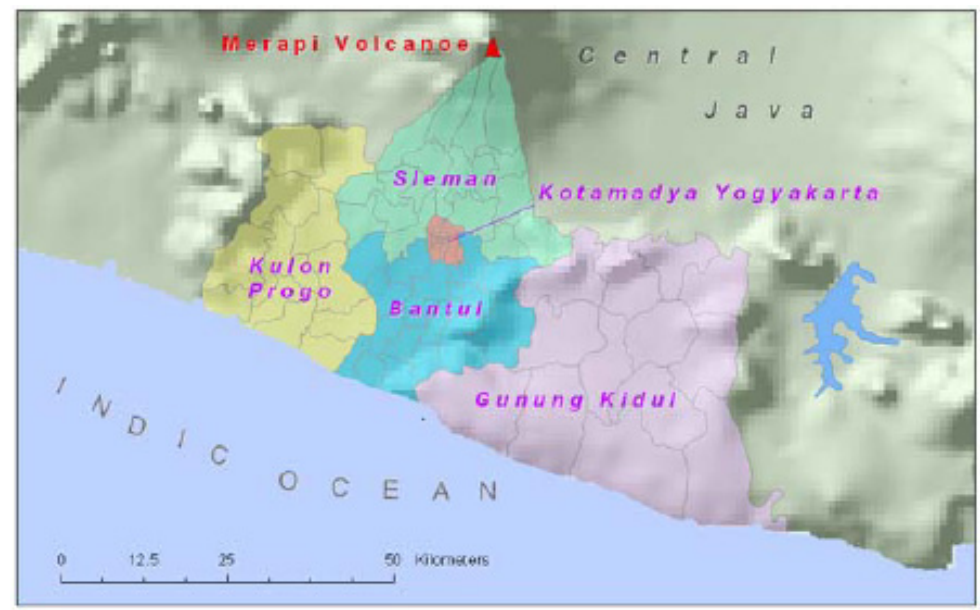

Figure 1: Topographic map of the Province of Yogyakarta on Java. 
Topographically Sleman can be divided into two major areas, the upper and medium slopes of the Mt. Merapi and the foothill area below. The upper slope represents the young Merapi cone with devastated to bare land and some thin gullies. The medium slopes comprise a complex of old and young Merapi products forming deep valleys, mainly in pyroclastic deposits. Smooth slopes and shallow valleys characterize the foothill area consisting of fluvial deposits.

The major soils according to US soil classification in the area are Andisols and Mollisols at the upper slopes of the Mt. Merapi and Inceptisols at the medium slopes and the floodplains of Mt. Merapi. Some Entisols and Vertisols can be found in the mountainous areas in the south of Sleman.

Land use in Sleman is stamped by a vertical zonal distribution according to the increasing slope of the Merapi volcano. At lower slopes from about 0 to $5 \%$ paddy fields dominate the mostly agricultural used area. From about 5 to $10 \%$ slope mainly rain feed agriculture of vegetables and cash crops can be found. Weather at slopes greater than $10 \%$ the land use is dominated by forest, shrubs and grassland.

\section{Estimating soil erosion costs}

To estimate the economic significance of soil erosion its physical dimension has to be determined, and linked and valued to changes in crop production and farming systems.

In this study soil erosion was determined using the Universal Soil Loss Equation (USLE). The model is widely used in science to estimate soil erosion at multiple scales (Renard et al. [12]; Turnage et al. [13]), and also commonly used with some adoptions under tropical conditions (Millward and Mersey [14]; Wiriosudarmo and Bisri [15]; El-Swaify [16]).

\subsection{Replacement cost method}

The so-called replacement cost approach estimates the forgone input which is necessary to overcome the negative effects of soil erosion (Kim and Dixon [8]; Dixon et al. [9]; Gunatilake and Vieth [10]; Krausse et al. [11]).

Usually only the fertilizer replacement as major costs is considered. Thus, the replacement costs can be seen as the costs to replace the lost nutrients and the additional energy, maintenance and labour work to apply the extra fertilizer to the fields. In the $\mathrm{i}^{\text {th }}$ land use of an area it can be presented as eqn (1):

$$
\begin{gathered}
R C_{i}=\left(S_{t}-S_{(t+1)}\right) \sum N_{i j} P_{j}+C_{i l}+C_{i r} \\
i=1 \ldots n, j=1 \ldots k
\end{gathered}
$$

where:

$R C_{i}$ is the replacement cost of nutrients in $\mathrm{i}^{\text {th }}$ category of land use, $\mathrm{Rp} / \mathrm{ha}$

$S_{t}-S_{(t+1)}$ ist he soil loss from time $\mathrm{t}$ to $\mathrm{t}+1, \mathrm{t} / \mathrm{ha}$ 
$N_{i j}$ is the quantity of $\mathrm{j}^{\text {th }}$ nutrient in $\mathrm{i}^{\text {th }}$ land use type, $\mathrm{kg} / \mathrm{t}$

$P_{j}$ is the price of $\mathrm{j}^{\text {th }}$ nutrient, $\mathrm{Rp} / \mathrm{kg}$

$C_{i l}$ is the cost of labor in spreading fertilizer, $\mathrm{Rp} / \mathrm{ha}$

$C_{i r}$ is the cost of repair and maintenance of damages due to soil erosion $\mathrm{Rp} / \mathrm{ha}$

Included in the calculation of the replacement costs are the major nutrient Nitrogen, Phosphorous and Potassium. Nutrient levels of eroded soil are usually not available. Therefore it is assumed that the nutrient level in the eroded soil and the farm soil are the same. Based on the assumption the amount of nutrients lost is calculated using representative soil nutrient analyses from the farm soils.

\subsection{Productivity change method}

The change in productivity approach determines the difference in crop yields with and without erosion, multiplied by the unit price of the crop, and less the variable costs of the production (Magrath and Arens [6]; Gunatilake and Vieth [10]). Although this seems straightforward and simple, in practice the quantification of the effect on crop yield losses is conceptually difficult. In this study the approach of Magrath and Arens [6] introduced for Java was used to quantify the changes in productivity.

They assumed that if output falls farmers adjust variable inputs in production to yield declines and that fixed costs remain fixed. Percentage productivity declines are denominated base on the response of sensitive and less sensitive crops. The result of this procedure is a linear decline in profits as productivity falls. To account for possible adjustments in cropping systems, farm budgets for a variety of representative dry land cropping systems across Java were constructed, and then used to estimate the effects of the yield losses from erosion on net farm incomes. This was done comprehensively for a single year.

They have estimated an average yield reduction on Java between 4-7\%, depending on soil type and crops planted. Using their results the costs for reduced yields were calculated by relating the lost yields to the average cross margin of the agricultural production in the region, based on prices of important cash crops and vegetables in the District Yogyakarta in 2002.

\section{Results and discussion}

\subsection{Soil erosion}

On most of the cultivated area in Sleman bench terraces or at least raised bed terraces are used. This is reflected by low erosion rates $<5 \mathrm{t} \mathrm{ha}^{-1} \mathrm{yr}^{-1}$ (Figure 2). At the upper part of the Merapi volcano at areas with steep slopes and badly maintained or no terraces erosion rates exceed by fare a sustainable level. Here erosion rates with more than $100 \mathrm{t} \mathrm{ha}^{-1} \mathrm{yr}^{-1}$ can be found at cultivated areas. 

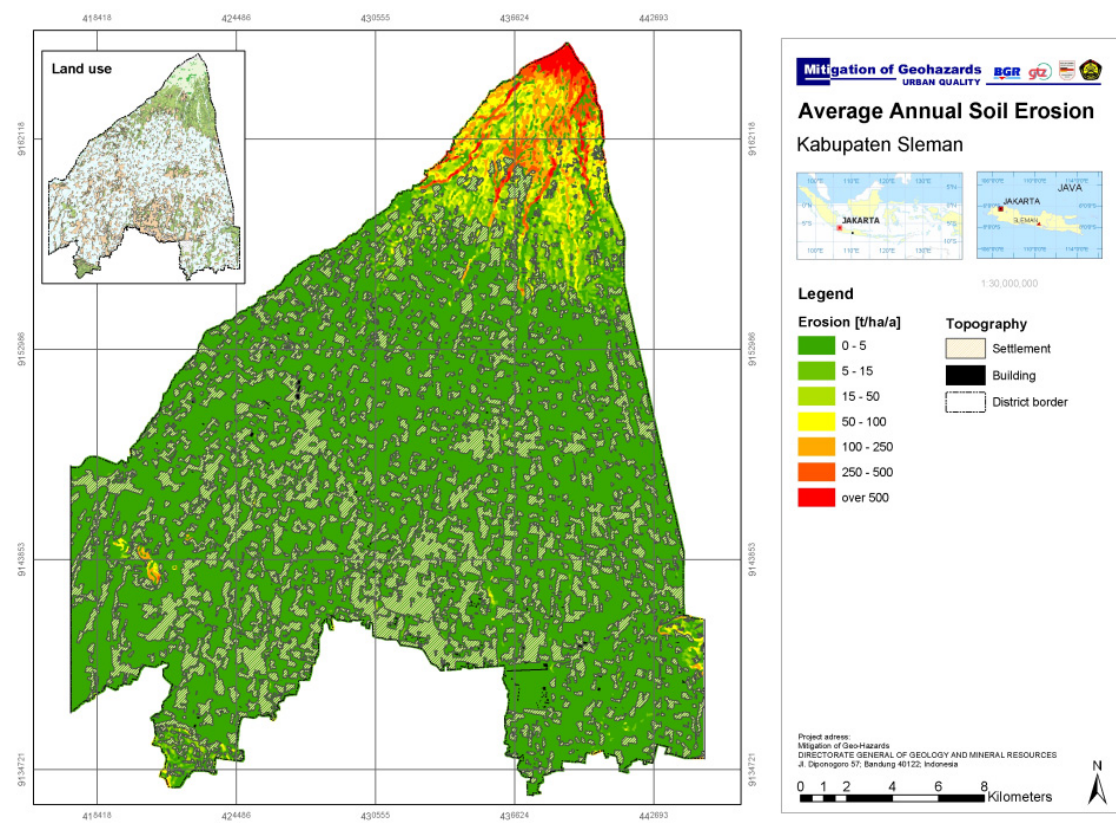

Figure 2: $\quad$ Map of the average annual soil erosion in the District of Sleman.

Areas with particularly high erosion rates at the top of the volcano with up to $500 \mathrm{t} \mathrm{ha}^{-1} \mathrm{yr}^{-1}$ are not cultivated, but consist of loose pyroclastic deposits triggering debris flows during heavy rains in the rainy season.

Similar erosion rates were found in other studies carried out on Java. Magrath and Arens [6] has estimated for steep slopes on Java erosion rates up to $500 \mathrm{t} \mathrm{ha}^{-1} \mathrm{yr}^{-1}$ with an average of $123 \mathrm{t} \mathrm{ha}^{-1} \mathrm{yr}^{-1}$ for "Tegal" land use (rain fed agriculture) and $87 \mathrm{t} \mathrm{ha}^{-1} \mathrm{yr}^{-1}$ for degraded forests. Kusumandri and Mitchell [17] found soil erosion rates for the Citarik watershed on West Java to be about $100 \mathrm{t}$ $\mathrm{ha}^{-1} \mathrm{yr}^{-1}$.

Although at most of the agricultural land in Sleman already some soil conservation is practiced, some areas at the upper slopes of the volcano and at some hilly parts in the south have significant soil erosion problems with more than $15 \mathrm{t} \mathrm{ha}^{-1} \mathrm{yr}^{-1}$. The area affected is 2737 ha with an average soil erosion rate of $30 \mathrm{t} \mathrm{ha}^{-1} \mathrm{yr}^{-1}$ (Figure 3). These areas took center stage in the estimation of the costs of soil erosion in Sleman.

\subsection{Soil erosion costs}

The costs to replace lost nutrients in these agricultural areas were estimated to be $14100 \mathrm{Rp} \mathrm{t}^{-1}$ soil, taking into account an average soil nutrient content of $\mathrm{N}=1.1$ $\mathrm{kg} \mathrm{t}^{-1}, \mathrm{P}=0.8 \mathrm{~kg} \mathrm{t}^{-1}$, and $\mathrm{K}=3.7 \mathrm{~kg} \mathrm{t}^{-1}$ and prices of common fertilizers in 2003 
$($ Urea $=1000 \mathrm{Rp} ; \mathrm{TSP}=1000 \mathrm{Rp} ; \mathrm{KCl}=1200 \mathrm{Rp})$. Thus, the replacement cost with an average soil erosion rate of $30 \mathrm{t} \mathrm{ha}^{-1} \mathrm{yr}^{-1}$ is $423000 \mathrm{Rp} \mathrm{ha}^{-1} \mathrm{yr}^{-1}$. The additional costs for energy, maintenance and labour work were estimated based on results from literature and expert experience to be $85000 \mathrm{Rp} \mathrm{ha}^{-1} \mathrm{yr}^{-1}$ or about $20 \%$ of the replacement costs. Thus, the total costs were estimated to be 508000 $\mathrm{Rp} \mathrm{ha}^{-1} \mathrm{yr}^{-1}$. However, the approach overestimates soil erosion costs, based on the conceptual assumption estimating the difference between erosion and "zero" erosion and the assumption that all nutrients lost would be available for plants in the long term, which is in reality in agriculture not realizable. On the other hand other effects like the loss of organic matter or water holding capacity are not considering.

On the bases of the change in productivity approach of Magrath and Arens [6] the average productivity loss at agricultural areas with significant erosion was calculated to be $160000 \mathrm{Rp} \mathrm{ha}^{-1} \mathrm{yr}^{-1}$. This seems to underestimate the actual costs of soil erosion. However, Magrath and Arens [6] "capitalized" the one year cost of erosion by a factor of 10 to obtain a total present value of current and future losses, assuming that one year loss in net income recurs over each successive year. On the other hand considering only plant available nutrients lost $\left(\mathrm{N}=1.1 \mathrm{~kg} \mathrm{t}^{-1} ; \mathrm{P}=0.45 \mathrm{~kg} \mathrm{t}^{-1} ; \mathrm{K}=0.8 \mathrm{~kg} \mathrm{t}^{-1}\right)$ within the replacement cost approach the average costs are comparable, with $250000 \mathrm{Rp}^{-}$ ${ }^{1} \mathrm{yr}^{-1}$ (Figure 3 ). These costs are equal to $\approx 17 \%$ of the average farmers net income per ha agricultural land.

A similar order of magnitude of soil erosion costs was reported by Krausse et al. [11] and Gunatilake and Vieth [10] for agricultural soils in New Zealand and Sri Lankan high land soils, respectively. Krausse et al. [11] estimated the actual costs for soils suffering significant erosion in New Zealand to range between Aus\$ 8 and Aus\$ $25 \mathrm{ha}^{-1}$, with an average erosion rate of $10 \mathrm{tha}^{-1} \mathrm{yr}^{-1}$. Considering the average erosion rate of eroded soils in Sleman $\left(30 \mathrm{tha}^{-1} \mathrm{yr}^{-1}\right)$ this would approximate between $135000 \mathrm{Rp}$ and $420000 \mathrm{Rp} \mathrm{ha}^{-1} \mathrm{yr}^{-1}$. Gunatilake and Vieth [10] estimated slightly higher soil erosion costs depending on the type of crop and the erosion rate with e.g. $\approx 200000 \mathrm{Rp}(21-25$ USD) for paddy fields and $\approx 600000 \mathrm{Rp}$ (68 USD) for market gardens.

On the other hand to minimise soil erosion rates soil conservation measures are necessary, which are not cost less. Adiningsih and Karama [18] estimated the additional annual costs for bench terraces and raised bed terraces compared to conventional farming practices in East Java to be 113 USD $(\approx 1$ million Rp) and 56 USD (500000 Rp), respectively. Thus, the costs for terracing are not covered by the benefits from reduced erosion alone. Other potential benefits like the possibility to intensify/change the agricultural production coming along with conservation measures have to be considered as well. Quantifying these benefits is very difficult, but point based studies comparing the net income of farms with and without conservation measures indicate that adequate soil conservation measurements can be economically worthwhile (Adiningsih and Karama [18]; Posthumus and De Graaff [19]). Adiningsih and Karama [18] showed that the net income of the farmers was by a multiple higher after changing to an integrated farming system with terraces. 


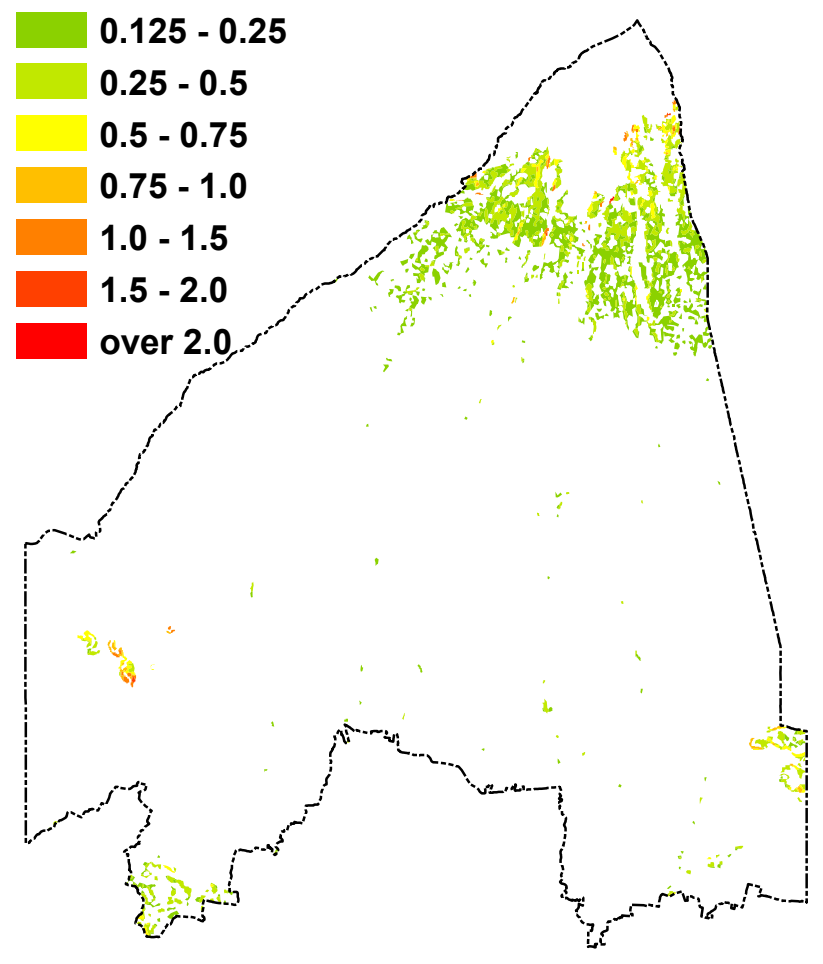

Figure 3: Map of the On-farm cost of erosion (at agricultural areas with significant soil erosion [million $\left.\mathrm{Rp} \mathrm{ha}^{-1} \mathrm{a}^{-1}\right]$ ).

Adventitiously, other decision factors like the availability of credits or the fact that in many countries soil conservation is not reflected in land prices makes it difficult or impossible for a farmer to decide if it is worthwhile to invest in a certain soil conservation measure. Nevertheless, information available on the costs of soil erosion and on possible benefits is an important economic factor to help farmers in their decision to invest in soil conservations measure.

Besides, not reflected in farmer's decision-making are off-site or external costs of soil erosion, but they play an important part of the economic impact of soil erosion. In many studies off-site cost are estimated to be higher than on-site costs. About these costs, which are not reflected by the markets prices, the society has to be concerned and against the background that decisions on pure economic basis usually only consider the next maximum 50 years, but sustainability of soil resources is a matter of the next centuries, soil conservation has to be a general goal for the society and can't be shouldered by the farmers alone. However, it is not easy to design appropriate policies to include the offsite or external costs into the decision-process of soil conservation on farm level. 


\section{Acknowledgements}

The project was funded by the Federal Minister for Economic Cooperation and Development, Germany. The Authors acknowledge the contribution of the Directorate General of Geology and Mineral Resources of Indonesia to the project.

\section{References}

[1] Uhl, C.J., Carl, C., Clark, H., Herrera, R., Ecosystem recovery in Amazon Caatinga forest after cutting, cutting and burning, and bulldozer clearing techniques. Oikos 38(3), pp. 313-320, 1982.

[2] Landa, R., Meave, J., Carabias, J., Environmental deterioration in rural Mexico: an examination of the concept. Ecological Applications 7(1), pp. 316-329, 1997.

[3] Lubchenco, J., Entering the century of the environment: a new social contract for science. Science 27(5350), pp. 491-497, 1998.

[4] Pimentel, D., Harvy, C., Resosudarmo, P., Sinclair, K., Kurz, D., McNair, M., Crist, S., Shpritz, L., Fitton, L., Saffouri, R., Blair, R., Environmental and Economic Costs of soil Erosion and Conservation Benefits. Science 267(5126), pp. 1117-1123, 1995.

[5] Wolman, M.G., Soil erosion and crop production: A worldwide perspective. Soil erosion and crop productivity, eds. R.F. Follett \& B.A. Stewart, ASA, CSSA \& SSSA: Madison, pp. 10-22, 1985.

[6] Magrath, W. \& Arens, P., "The Costs of Soil Erosion on Java: A Natural Resource Accounting Approach", Environment Department Working Paper No. 18, Washington D.C.: The World Bank, 1989.

[7] Barbier, E.B., The Economics of Soil Erosion: Theory, Methodology and Examples. Special Papers, Fifth Biannual Workshop on Economy and Environment in Southeast Asia, Singapore, 1995.

[8] Kim, S.H., Dixon, J.A., Economic valuation of environmental quality aspects of upland agricultural projects in Korea. In: Doxon, J.A., Hufschmidt, M.M. (eds.). Validation techniques for the environment: A case study workbook. Baltimore: Johns Hopkins University, 1986.

[9] Dixon, J.A., Scura, L.F., Carpenter, R.A., Sherman, P.B., Economic analysis of the environmental impacts. London, Earthscan Publication Ltd, 1994.

[10] Gunatilake, H.M., Vieth, G.R., Estimation of On-site Cost of Soil Erosion: A Comparison of Replacement and Productivity Change Methods. Journal of soil and water conservation 55(2), pp. 197-204, 2000.

[11] Krausse, M., Eastwood, C., Alexander, R.R., Muddied waters Estimating the national economic cost of soil erosion and sedimentation in New Zealand. Manaaki Whenua landcare research, Palmerston North, 2001.

[12] Renard, K.G., Foster, G.R., Weesies, G.A., McCool, D.K., Yoder, D.C., Predicting soil erosion by water: a guide to conservation planning with the 
Revised Universal Soil Loss Equation RUSLE. Handbook No. 703. US Department of Agriculture, 404 pp., 1997.

[13] Turnage, K.M., Lee, S.Y., Foss, J.E., Kim, K.H., Larsen, I.L., Comparison of soil erosion and deposition rates using radiocesium, RUSLE, and buried soils in dolines in East Tennessee. Environmental Geology, 29, pp. 1-9, 1997.

[14] Millward, A.A., Mersey, J.E., Adapting the RUSLE to model soil erosion potential in a mountainous tropical watershed. Catena, 38, pp. 109-129, 1999.

[15] Wiriosudarmo, S., Bisri, D.H., Use of environmental geological information to plan erosion control in the upper part of the Citanduy catchment, West Java province, Indonesia. Sixth Regional Congress on Geology, Mineral and Hydrocarbon Resources of Southeast Asia, 1987.

[16] El-Swaify, S.A,. Susceptibilities of certain Tropical Soils to Erosion by Water. In: Greenland, D.J. and Lal, R. Soil Conservation and Management in the Humid Tropics. John Wiley \& Sons, New York, 1977.

[17] Kusumandri, A., Mitchell, B., Soil erosion and sediment yield in forest and agroforestry areas in West Java, Indonesia. Journal of Soil and Water Conservation, 52(4), pp. 376-380, 1997.

[18] Adiningsih, J.S., Karama, A.S., A sustainable upland farming system for Indonesia. http://www.fftc.agnet.org/library/abstract/eb354b.html, 1992.

[19] Posthumus, H., De Graff, J., Cost-benefit analysis of bench terraces, a case study in Peru. Land Degradation \& Development, 16(1), pp. 1-11, 2004. 